\title{
Jovens em acolhimento institucional prolongado: entre a vida governada e a liberdade
}

\author{
Celecina Sales \\ Francisca Helena Rocha \\ Universidade Federal do Ceará
}

\section{Resumo}

Este estudo problematiza o estatuto de vida que constitui os sujeitos que se encontram sob a proteção social. Sob a perspectiva da biopolítica, esta pesquisa foi realizada em uma entidade de acolhimento institucional, na cidade de Fortaleza-CE, com jovens entre 17 e 20 anos e com experiência de institucionalização prolongada. A prática de acolhimento institucional engendra condições de inclusão/exclusão que permitem aos/às jovens ultrapassar as experiências e os limites institucionais. Confirma o sentido biopolítico dos saberes e das práticas vivenciadas pelos jovens acolhidos; subjetividades marcadas por sujeição institucional e por dificuldade de exercício de liberdade.

Palavras-chave: Biopolítica. Acolhimento institucional. 


\section{Youth in institutional shelter for extended periods of time: between freedom and governed life}

This study problematizes the state of life in which are the subjects under social protection. Under the perspective of biopolitics, this research was conducted in an institutional host entity in Fortaleza-Ce, with young people between 17 and 20 years of age and with a prolonged experience of institutionalization. The practice of institutional care engenders conditions of inclusion / exclusion that allow young people to overcome the institutional experience and limitations. This confirms the biopolitical tenor of the knowledge and practices experienced by the young people welcomed - subjectivities marked by institutional subjection and by difficulty in the exercise of freedom.

Keywords: Youth. Biopolitics. Institutional shelter.

\section{Jóvenes en acogimiento institucional extendido: entre la libertad y la vida dirigida}

Este estudio analiza la situación de la vida que constituye a los sujetos que caen bajo la protección social. Desde la perspectiva de la biopolítica, esta investigación se realizó en una entidad de acogimiento institucional en la ciudad de Fortaleza, con jóvenes entre 17 y 20 años y con experiencia de institucionalización prolongada. La práctica institucional engendra condiciones para inclusión/exclusión que permite a los/las jóvenes superar las experiencias y los límites institucionales. Confirma el sentido político de conocimientos y prácticas experimentadas por los jóvenes acogidos; subjetividades marcadas por sujeción institucional o subordinación y por la dificultad del ejercicio de la libertad.

Palabras-clave: Jóvenes. Biopolítica. Acogimiento institucional. 


\section{Introdução}

Abandonadas, protegidas, crianças e adolescentes que vivem em acolhimento institucional têm suas vidas traçadas até completarem 18 anos e depois? 0 foco deste trabalho é a prática social do acolhimento institucional de jovens com idade entre 17 e 20 anos na cidade de Fortaleza-CE-Brasil'. Esses jovens tiveram experiência prolongada em entidades de acolhimento institucional e encontram-se, atualmente, prestes a deixar esse espaço, em face da proximidade e/ou ultrapassagem da idade-limite permitida, 18 anos, para permanecer no local.

Atualmente, 0 acolhimento institucional, em sua maioria, funciona sob a gestão de Organizações Não Governamentais (ONGs), que exercem importante papel nas disputas e estratégias biopolíticas que remontam à origem do social no trato com o segmento infantojuvenil considerado em situação de risco.

A pesquisa de campo foi realizada durante o ano de 2011. A seleção da entidade partiu de um levantamento realizado em 2010 nas unidades de acolhimento institucional de Fortaleza-CE, quando constatamos que, das 23 entidades visitadas, 10 atendiam adolescentes na faixa etária entre 15 e 18 anos e nos chamou atenção a presença de jovens com idade superior a 18 anos em 5 dessas unidades.

Os sujeitos da pesquisa foram 15 jovens com faixa etária compreendida entre 17 e 20 anos, dos quais 13 tinham experiência de acolhimento institucional prolongado, critério fundamental ao atendimento do objetivo do trabalho. Foram priorizados os discursos concedidos por 13 jovens residentes, além de gestores, técnicos e educadores colhidos por meio de entrevistas não diretivas. Durante seis meses fizemos observação nos horários das refeições, de lazer e de eventos sociais, que foram registradas em um diário de campo. Também realizamos entrevistas que foram gravadas e transcritas, atentando-se para os gestos não verbalizados: gestos, emotividade, silêncio, choro, volume e timbre de voz, como fontes importantes na análise do instrumental utilizado. Ressaltamos a garantia do anonimato e de sigilo das informações recebidas, o que facilitou a espontaneidade dos discursos. Solicitamos que criassem nomes fictícios para si e justificassem a escolha. Outra fonte de pesquisa importante foram os prontuários contendo documentos jurídicos e psicossociais dos entrevistados.

Procuramos problematizar as condições de "inclusão/exclusão" que permitem ultrapassar as experiências e limites institucionais de onde são atendidas crianças e adolescentes acolhidos, com fundamento no prisma da biopolítica e de uma "governamentalidade" neoliberal, posta em prática, também, pelas políticas de assistência social. Nossa questão é saber: que estatuto de vida é direcionado aos

1. Este trabalho é um recorte da pesquisa realizada no Doutorado de Educação da Universidade Federal do Ceará, sob a orientação da Profa Dra. Celecina de Maria Veras Sales. Não houve financiamento para a realização da pesquisa, contudo é importante esclarecer que a doutoranda Francisca Helena Rocha teve acesso facilitado por ser assessora técnica da Coordenadoria da Infância e da Juventude - Ceará. A pesquisa ocorreu dentro dos procedimentos éticos e com autorização do órgão competente. 
sujeitos que se encontram sob a medida protetiva de acolhimento institucional? Que modos de subjetividade os elementos institucionais (prática de acolhimento institucional - estratégia biopolítical produzem nos jovens que são alvo da política de proteção social na sociedade brasileira?

Nosso objetivo proposto foi apreender quais e como se relacionam os saberes que circulam a prática da medida protetiva de acolhimento institucional e os modos de subjetividade que essa engrenagem biopolítica produz no jovem inserido, por um longo período, em entidades dessa natureza.

Sob o enfoque biopolítico, o sujeito é objetivado por um saber médico estatístico voltado para a projeção dos fatores de risco, cujo objetivo é ultrapassar o corpo do indivíduo e se estender ao corpo coletivo, corpo-espécie, corpo-população. Esse saber atua sobre os fatores de risco que ameaçam a população e traçam as formas de intervenção estabelecidas em torno dele, visando a sua contensão. Concretiza seus objetivos com suporte em uma engrenagem médica-jurídica que, por sua vez, produz uma subjetividade submissa, assujeitada, dificultando condutas de resistência e oposição.

A relevância desta reflexão reside, portanto, na tentativa de superar a lacuna de trabalhos que retratam a prática social do acolhimento institucional, direcionada para uma rede de ferramentas operacionais, e contribuir com a pesquisa crítica fundamentada em torno de três faces: biopoder-saber, estratégia (prática) e subjetividade.

Com base na denominação jurídica, aliás, redundante, "Nascido Vivo”, dada a um formulário expedido por ocasião da saída da mãe do hospital após o parto, informando os dados de identificação do recém-nascido e da mãe, requisito indispensável para a feitura do registro de nascimento da criança junto aos cartórios de todo o território nacional, surgiu a ideia de assim, também, chamarmos o estatuto de vida apresentado ao segmento infantojuvenil investigado.

0 enfoque teórico baseado em Michel Foucault surge neste trabalho em face das importantes análises que o autor realizou acerca da natureza biopolítica e de suas implicações no binômio poder e vida. Procuramos, ainda, estabelecer um diálogo com outros autores que, seguindo o rastro foucaultiano, nos ajudaram a pensar sobre os processos de inclusão-exclusão contemporâneos, tais como: Antônio Negri, Michel Hardt, Giorgio Agamben, Zigmunt Balman, Peter Pál Pelbart, Deleuze, Rabinow, Rose, Veiga-Neto, Larossa e Sylvio Gadelha, entre outros.

Para refletir sobre o processo educativo na instituição de acolhimento investigada, utilizamos também Erving Goffman, porque este autor, assim como Michel Foucault, auxilia no estudo dos mecanismos de controle e punição a que sujeitos institucionalizados estão submetidos. 0 conceito de "instituição total" e estigma de Goffman (2005) foram importantes para pensar o cotidiano dos/as jovens em acolhimento.

Foucault direcionou, inicialmente, a sua concepção de biopoder ao poder que incide sobre a vida, e a biopolítica ao dispositivo estratégico utilizado para exercer 
o controle sobre o corpo-indivíduo e o corpo-população. Em seguida, a sua concepção de biopolítica se encaminhou para o âmbito da arte de governar as ações alheias, ação que interfere nas ações do outro, denominada por ele de "governamentalidade", cujo significado é diferente da definição de governo como instância que executa ações governamentais. A inclusão se torna, assim, o imperativo fundamental, pois permite o funcionamento da "governamentalidade" neoliberal, na medida em que situa os sujeitos em uma rede de saberes, procurando dotar-lhes de condições que permitam a eles a circulação e participação, por maior tempo possível, no interior do universo social e econômico.

Nossa reflexão sob essa óptica pode contribuir para o conhecimento dos pilares que fundamentam essa nova modalidade de governo da vida, pois, somente apreendendo como se processa essa engrenagem, será possível aplicar esforços para desnaturalizar, desconstituir e desarmar o que está posto e assim sinalizar uma mudança de trajetória que privilegia um caminho diverso do atual.

Sem a pretensão de trazermos, por meio dos sujeitos investigados, a voz anônima dos muitos outros que estão com suas vidas silenciadas, sobrevivendo à semelhante "vida nua", e muito menos de falar em nome dos sujeitos investigados, nosso trabalho procura visualizar o contexto analisado, sob o prisma da biopolítica da "governamentalidade" neoliberal, para poder destacar como se constitui no interior das práticas sociais atuais o governo da conduta do homem e como cada um, com sua singular experiência de vida, carrega consigo um universo a ser apresentado e, em comum, a tentativa de melhor conviver socialmente com a opção que lhes restou. Vida nua foi teorizada por Agamben (2010), como "[...] a vida reduzida ao seu estado de mera atualidade, indiferença, disformidade, impotência, banalidade biológica". (Pelbart, 2006, p. 11)

A importância do conhecimento da natureza do estatuto biopolítico de "Nascido Vivo" (sic), cujo significado expressa a vida tomada apenas no sentido biológico, destituída de valores humanos, de laços familiares, fruto do abandono que fundamenta o caráter de risco que seus detentores representam, tendo a engrenagem médico-jurídica possibilitado o surgimento do espaço para o seu aparecimento.

\section{Biopolíticas e práticas institucionais: arte de governar}

As políticas de inclusão social de acolhimento institucional apontadas nos documentos oficiais do século XX são justificadas, de forma recorrente, em face da "situação de risco" a que crianças e adolescentes estão expostos.

Um local lou uma situação), para ser considerado de risco, implica ter sido, anteriormente, mensurado, observado. Fundamenta-se num levantamento prévio de pessoas, objetos e situações diagnosticadas com apoio nos dados revelados.

A combinação dos fatores que induzem à categorização do "risco" se sobre- 
põem aos atos individuais que lhes são inerentes. Assim, a estatística foi se transformando em dispositivo tecnológico da "governamentalidade" contemporânea. Mediante o efeito poder/saber que a estatística detém, foi possível cartografar os locais e as situações de risco a que estão expostas as crianças e adolescentes pobres, das famílias destituídas de condições necessárias à sobrevivência. As necessidades passam, assim, a ser justificadas por meio dos números, que têm como finalidade tanto a condução da intervenção como a exposição dos resultados provenientes das ações assistenciais efetivadas. No âmbito da racionalidade política neoliberal, o modelo quantitativo estatístico facilita as avaliações para aferição dos resultados, por serem passíveis de mensuração, comparação e verificação por parte dos agentes externos à ação.

São os números que justificam se o ambiente e o comportamento familiar constituem indicadores potenciais da situação de risco, que, somados à pobreza, à baixa escolaridade, ao uso abusivo de álcool, maus-tratos e violência generalizada, atuam como fatores preponderantes. Estes, entre outros, se tornam os indicadores que comprometem a integridade física e intelectual dos sujeitos, principalmente dos que se encontram em desenvolvimento; especialmente crianças e adolescentes que se tornam ameaças à sociedade por contrariar as normas vigentes, que têm como referência a casa, representando espaço de aconchego, de abrigo, e a família, a obrigação de garantir o cuidado, a segurança, o conforto e a afetividade aos sujeitos sob sua guarda.

Para analisarmos a prática do acolhimento das crianças e adolescentes investigados, recorremos a Foucault (2008), porque ele oferece ferramentas metodológicas e conceituais importantes para pensar a biopolítica como forma de "governamentalidade" contemporânea utilizada para dirigir a conduta humana. Assim, inicialmente, faz-se necessário aqui refletir sobre o significado dado à expressão "situação de risco", condição determinante na seleção de quem deve ou não ser incluído nas práticas sociais da gestão social.

Consideramos importante levar em conta a situação individual das famílias cujos descendentes foram "capturados" pelos dispositivos biopolíticos de "governamentalidade" atuais, como a política social de medida protetiva de acolhimento institucional. A necessidade de inclusão das crianças e dos adolescentes em tais práticas sociais passa a contar, como critério fundamental de definição, com a condição de "situação de risco", posta pelo saber estatístico. 0 objetivo é intervir no sentido de criação de normas, estratégias e de ações para tornar esses indivíduos sujeitos dóceis, subservientes e governáveis, por via da gestão das condutas individuais e coletivas.

Entrar no contexto da institucionalização significa ser reconhecido em "situação de risco", implica ser portador de uma história de vida marcada por uma situação que foge à norma, estatuto que assumem e que os põe em relação de diferença a essa norma, cujos motivos fogem ao entendimento das crianças pequenas que povoam as entidades destinadas a lhes dedicar cuidados e proteção 
ante a impossibilidade de isso ser feito por suas famílias de origem.

Até o ano de 2002, existia uma entidade governamental em Fortaleza denominada "SOS Criança", espaço no qual as crianças e os adolescentes eram, inicialmente, admitidos. Essa casa exercia a atribuição de ser o primeiro lugar de acolhimento dos "abandonados", dos "desprotegidos", dos "pobres" dos que para lá eram levados por se encontrarem em "situação de risco", representando, portanto, uma ameaça potencial à ordem instituída. Esse era o lugar original de triagem, de definição de destinos, dos outros lugares que iriam marcar, desde então, a trajetória institucional de muitas daquelas crianças que lá chegavam.

Dependendo do motivo e da faixa etária do acolhido nesse espaço de passagem inicial, procedia-se ao direcionamento da criança ou adolescente para a unidade de acolhimento adequada, "Cada indivíduo em seu lugar; e em cada lugar um indivíduo" (Foucault, 1987, p. 131), um lugar determinado pelos profissionais da área social e jurídica como provisório, mas, em se tratando dos sujeitos pesquisados, esse período parece não ser valorizado.

As entidades, após o recebimento das crianças, comunicam ao juiz o acolhimento e os motivos para isso. Inicia-se, então, um rito jurídico burocrático e investigativo das condições do retorno da criança acolhida ao lar de origem ou da adoção por uma família substituta. Acontece que, diante do estatuto de desvalor que essas vidas representam, da grande demanda de acolhimento e poucos profissionais da área social e jurídica para atuar em torno dos casos, o tratamento realizado, muitas vezes, não se concretiza de forma adequada à necessidade, acarretando a permanência de crianças na instituição indevidamente, em alguns casos, com as famílias de origem aguardando a autorização para levar seus filhos para casa.

Estes fatos expõem um exemplo patente do que significa ser corpo, ser vida humana, no contexto biopolítico do Ocidente contemporâneo; uma espécie de nova encarnação do Homo Sacer de Agamben (2010, p. 182), “[...] que se apresenta como um limiar da absoluta indistinção entre direito e fato, norma e vida biológica".

As entidades de acolhimento institucional, como um dos campos biopolíticos contemporâneos, parecem não ter pressa ao lidar com o tempo de permanência dos acolhidos, a julgar pela lenta cadência de movimentos do corpo de gestores que thes presta serviços e do Poder Judiciário a ele atrelado. Isso demonstra que no cotidiano a condução dessas vidas, desprovidas de reconhecimento jurídico, dinâmica que move o contexto sociojurídico e os poderes implicados na relação entre os seus representantes e o sujeito acolhido institucionalmente, motivo que torna esses episódios eventos naturalizados, banalizados. Com o vínculo inexistente entre a simples vida nua, condição de "nascido vivo" (sic) dos acolhidos e os seus devidos direitos de cidadania, o acontecimento citado indica que o conceito jurídico-político de cidadão, como referencial crítico e emancipatório, não consegue dar resposta ao problema dessa ordem.

0 registro oficial de uma criança e/ou adolescente no acolhimento institucional 
ocorre no momento em que a sua chegada é informada à autoridade judicial. Desde então, se configuram a institucionalização, um longo caminho a ser percorrido e mais episódios de desencontros do que de encontros entre os que se candidatam e os que aguardam uma oportunidade para constituir uma família pela via adotiva. Durante o período de acolhimento, os/as sujeitos/as acolhidos/as passam a ser "patrimônio" da instituição. A totalidade da experiência cotidiana desses/as jovens segue uma rotina institucional sem rupturas (Goffman, 2005), por isso os/as entrevistados/as mostram-se desagrados/as em relação a vida institucionalizada.

Todo dia é a mesma coisa, parece que hoje é ontem. Todo dia a mesma coisa é chato também. Eu queria que minha vida mudasse, de qualquer jeito, mas mudasse. (Gabriela, 17 anos)

Observamos que as vidas dos/as sujeitos/as acolhidos/as, embora mudando constantemente de espaços de acolhimento, continuam retratando a vida nua dos incluídos no segmento considerado de menor valia, podendo ser passível de sofrimento, mas, por se constituírem em vidas insacrificáveis, aos responsáveis pelas práticas de atos de violência não incide punição. Nesse patamar, todos/as podem ser inocentados/as, cujas condutas profissionais e sociais estiveram implicadas com o enquadramento dos/as infantes acolhidos/as na nova categoria jurídica "de vida sem valor" contribuindo para "[...] a fixação de um limiar além do qual a vida cessa de ter valor jurídico e pode, portanto, ser morta sem que se cometa homicídio." (Agamben, 2010, p. 135). De acordo com o autor, toda a sociedade contemporânea decide sobre os critérios, fixa os limites, define o limiar além do qual a vida deixa de ser relevante, deixa de ter valor jurídico e se torna indigna de ser vivida, determinando quais são os seus "homens sacros". Uma espécie de vida nua, "nascido vivo" (sic) que ameaça marcar presença em cada corpo biológico, em cada indivíduo, pela simples condição de ser vivente, compondo o novo horizonte biopolítico na contemporaneidade.

\section{Percurso do acolhimento institucional dos/as jovens}

Do universo de dez entidades de acolhimento institucional ligadas à Secretaria Estadual de Ação Social, cinco delas funcionam na sistemática da gestão partilhada com uma ONG, regime de cogestão, significando uma gestão em que o governo é o proprietário do imóvel institucional, mantendo na coordenação um servidor público, e, na composição da equipe técnica/administrativa, uma pequena quantidade de funcionários/as públicos/as e um maior contingente de colaboradores/ as terceirizados/as. As outras cinco restantes são mantidas sob a modalidade da 
gestão descentralizada, ou seja, todos/as que lá trabalham são prestadores/as de serviço contratados pela ONG gestora, que também se responsabiliza pela locação do espaço físico e coordenação dos trabalhos desenvolvidos em cada uma das entidades sociais por ela responsabilizada. Em ambas as situações - regime de cogestão ou gestão descentralizada - o Governo Estadual realiza um trabalho de supervisão.

Em uma das entidades de acolhimento visitadas, as crianças recebidas estão na faixa etária compreendida entre zero e sete anos de idade. São acolhidas cerca de 80 crianças, constantemente.

Passados os sete primeiros anos de institucionalização, as crianças são transferidas de entidade e, portanto, deixam a escola, o dormitório, os/as colegas, a professora. 0 sentimento de estranhamento de um novo lugar será vivenciado, inclusive a posição que ocupam, uma vez que no antigo espaço lideravam por serem os/as maiores da casa. No próximo abrigo, passarão a ser os/as menores. Em alguns casos, existe um rito de passagem que consiste em um trote. Um acontecimento dessa ordem foi ressaltado por um entrevistado, ao se referir à sua primeira experiência de transferência de unidade de acolhimento aos sete anos de idade.

No começo foi ruim. É porque no começo o mais difícil é lidar com o meio, assim, com os meninos. Quando chega, já tem trote. É bom você se acostumar logo assim em todo canto. Em todo abrigo tem trote. 0 pior foi no [...]. Foi um monte de menino ficar me chutando, me cuspindo, e isso foi ruim pra mim. Sabia que lá nessa época que eu morava lá nesse [...], lá era tudo desarrumado [...] dizia que não via as coisas. Assim, lá pra eles é normal, os meninos também de lá são tudo grandão, mas só que depois eu não tinha mais medo deles, não. (João, 20 anos)

Na segunda entidade, o período de permanência se expira ao completar 14 ou 15 anos. Novamente outra etapa de vida inicia. Surge o terceiro espaço físico onde passam a habitar com novos educadores/as e companheiros/as. Entretanto, a rotina permanece semelhante. Um novo período de adaptação recomeça e a esperança de encontrar uma nova família, aos poucos, desaparece.

Os sujeitos acolhidos vão sendo transferidos de acordo com critérios pertinentes à conveniência das instituições. As suas permanências em cada entidade habitada têm um período a ser obedecido. Grupos de irmãos com idades variadas são distanciados. Cada um é enviado para a instituição encarregada daquela faixa etária. A legislação, embora se oponha à separação de irmãos, não é observada. Em cada lugar, uma nova história de vida vai sendo constituída, mas os registros não pertencem aos seus/suas protagonistas. Seguem, na melhor das hipóteses, para as empoeiradas prateleiras dos arquivos institucionais. Eles e elas se deslocam levando consigo apenas as próprias lembranças que passam a fazer parte de suas memórias solitárias. 
As falas dos/as jovens revela o que Goffman (2005) denomina como "eu" "mortificado", ou seja, ao ingressarem na instituição, ocorre o processo de expropriação da sua própria história.

Ninguém conhece a minha história. (Messias, 19 anos)

Eu não sabia nem meu nome; fiquei sabendo só aqui mesmo. (Gabriel, 19 anos)

Ninguém sabe se meu pai morreu, se minha mãe morreu, não sabe. Eu perguntava como é o nome da mãe, do pai, ninguém sabe se tão morto, se tão vivo. (Wesley, 19 anos)

A condição de "nascido vivo" (sic) dispensa a existência de registros de suas trajetórias, de suas memórias. Não ser portador/a de sua história faz parte das estratégias de "governamentalidade" contemporânea, na medida em que busca estabelecer com maior facilidade o controle sobre a vida humana, conduzindo a forma de agir, sentir, se colocar diante de si, do mundo e de pensar acerca da vida que levam.

A constituição do estatuto de vida do/a adolescente acolhido/a institucionalmente por um período prolongado requer lembrar que as políticas de proteção social são direcionadas à contenção do risco que esses/as sujeitos/as oferecem à sociedade caso fujam do alcance das instâncias normativas de regulação social. Ressaltamos que os dispositivos biopolíticos de "governamentalidade" existentes na atualidade investem em estratégias que atuam numa sistemática diferente das práticas de coerção e disciplinamento, anteriormente aplicadas nos modelos tradicionais. Apresentam técnicas sutis, dissimuladas, que atuam na maneira de pensar e de agir de forma ilimitada, pois agem na produção da subjetividade contemporânea. A própria mudança da denominação “Abrigo de Menor", expressão que carrega estigma e rejeição, para "Entidade de Acolhimento Institucional”, sinaliza uma dessas situações; porém, a finalidade de moldar os/as assistidos/as sob o formato de corpos dóceis e governáveis permanece.

0 conhecimento do contexto institucional tornou-se fundamental para a compreensão das relações de saber/poder/verdade/subjetividade estabelecidas, bem como dos atos de obediência e de verdade. Para nos aproximar da realidade buscamos conhecer os discursos e a prática institucional que acontece no contexto da entidade pesquisada, bem como observar, escutar os/as jovens acolhidos/as e as manifestações de verdade que circulam no dito espaço de acolhimento investigado. 


\section{Jovens e a família}

Ao ouvirmos os relatos dos/as entrevistados/as sobre as lembranças e sentimentos de pertencimento à família, deparamos com histórias diversas. Entre elas, as que se referiam ao encontro da família por meio dos sonhos, única possibilidade de reencontro.

Lucas, 19 anos, chegou à entidade com menos de um ano de idade. Os registros presentes em seu prontuário informam que seus pais tinham oito filhos e sua genitora havia falecido, mas ele parece não ter conhecimento de sua história e garantiu que nunca soube de nenhum dado relacionado à sua origem. 0 jovem e a irmã, ainda hoje residentes na instituição, foram disponibilizados para adoção, mas não conseguiram uma família que os adotasse. Situações como essa levam os/as jovens a se perceberem diferentes e se perguntem por que outras crianças conseguiram ser adotadas e eles/as não. Mesmo sem ter total clareza desse processo, os/as jovens se sentem sem aceitação social plena, estigmatizados (Goffman, 1975). Para Goffman (1975, p. 12) "a sociedade estabelece os meios de categorizar as pessoas e o total de atributos considerados como comuns e naturais para os membros de cada uma dessas categorias".

Na fala desse jovem aparece a marca dolorosa da ausência da família e as "táticas de adaptação" (Goffman, 1975), que ele desenvolve para enfrentar seu cotidiano.

Lembrança da minha mãe que eu sinto, de ter mãe, pai, irmão, eu sinto é muito. Às vezes eu até sonho com a minha mãe, que eu voltava pra casa dela, mas nunca ela apareceu. (Lucas, 19 anos)

A recordação da família expressa na fala do jovem demonstra que a alternativa da vida institucionalizada não supera as perdas afetivas. Embora a instituição represente a casa, o lugar do acolhimento, ela também significa o confinamento e o isolamento social.

Caíque, 19 anos, tem três irmãos, todos mais novos, dos quais, juntamente com a mãe, ele nunca mais ouviu falar. Ainda hoje relembra os detalhes da vida em família e assevera que a procura deles será a meta perseguida ao sair da entidade.

Ela (a mãel arranjava os empregos e eu ficava em casa. Varria a casa, limpava tudo. Meus irmãos ficava só assistindo televisão, sentado; eu que fazia as coisas. Às vezes eles tentavam ajudar, mas eu dizia "num precisa não, pode continuar aí" e deixava eles lá na televisão. "Faça aí os dever e depois eu vou ver se tá certo". Aí era assim: à noite eles ia dormir, eu dava um beijo. Se minha mãe tivesse condições, ainda tava fazendo isso. Eu me perdi dela, eu fiquei no meio da rua e uma pessoa me encontrou. Ela tava me procurando. Eu não sabia que ela tava me procurando. Aí eu tava chorando porque eu tava com saudade... Eu gosto muito de dormir pra eu sonhar com a minha família e pro tempo passar. (Caíque, 19 anos) 
O sentimento de família, cuja convivência foi tão reduzida, no imaginário de Lucas se faz presente nos seus sonhos. E é em torno da família que Lucas e os demais entrevistados direcionam os principais projetos de vida. Esse fato é identificado nas diversas pesquisas realizadas com jovens pertencentes a segmentos socioeconômicos e culturais² variados.

Para todos/as esses/as jovens, a separação da família torna a vida no abrigo mais dolorosa. Talvez por isso eles/as projetem e idealizem o reencontro familiar.

Caíque, pelo que pudemos observar, expressa sofrimento em decorrência da separação da família e, embora ninguém tenha conhecimento de onde encontrála, ainda se lembra do nome da rua onde morava com a mãe e os irmãos, pretendendo se dirigir até o local, com a esperança de conseguir alguma informação que o ajude a contatá-los. Para ele, viver distante de sua família é um contexto tão difícil de enfrentar que prefere passar o tempo dormindo para vivenciar a sua realidade por menor período.

Messias, 19 anos, dos quais 18 deles vivendo em entidades de acolhimento, não sabe a sua origem. Disse que já perguntou, mas ninguém a conhece. Ao longo de sua fala, era recorrente a melancolia expressada em ter acompanhado a oportunidade que alguns companheiros tiveram e a ele não foi possibilitada. Já Gabriel também, deixa transparecer na sua fala o estigma da institucionalização que chegou apenas a ele no universo de sua família.

0 meu amigo, ele não tinha um parente, aí ele arranjou, encontrou a família dele mesmo, aí tá morando com eles. Tá gordo. Ele era dessa finura. (Messias 19 anos)

Pai eu não tenho não, tenho padrasto. Mas irmão eu tenho: três irmãos mais velhos. Um tá morando numa casa alugada, as outras cuida da minha avó, minhas duas irmãs, e eu sou do abrigo aqui, sou o único de abrigo. (Gabriel, 19 anos).

“Ser de abrigo" é ser privado do convívio da família, é partilhar a "vida íntima da instituição", isto pressupõe obrigações, cumprir rotinas diárias, as regras e proibições do abrigo (Goffman, 2005). Nesse sentido, podemos pensar o abrigo a partir do conceito "instituição total" de Goffman (2005), ou seja, aquela instituição que atende os indivíduos em situações semelhantes, impondo uma vida fechada por um período de tempo. Em síntese, a instituição que detém o controle total da vida dos internos.

A vida no abrigo, a espera pela adoção que não ocorreu, gera expectativas e frustrações. Em todas as falas percebemos a necessidade dos/as jovens de ter uma família adotiva ou a sua própria família de volta. Mesmo para aqueles/as que

2. Rocha (1999), em pesquisa realizada com adolescentes em situação de exploração sexual comercial na Av. Beira Mar, de Fortaleza; Sales (2006), com jovens de assentamentos rurais do MST; Bonfim (2009), com adolescentes com experiência de rua e em situação de abrigo. 
não tiveram convívio familiar, é muito importante criar vínculos duradouros e reconstruir sua história.

Gabriel enfatiza ser "o único de abrigo" da sua família; demarca a sua condição de exceção, de inferioridade, daquilo que foge à norma familiar - ser de abrigo - o limiar entre o que significa se considerar na condição de abrigado ou ser membro integrante da família, como espaços contraditórios. Essa condição reflete o estatuto de vida demarcado pela sociedade que não apenas classifica os níveis de importância de cada um, como também impõe aos seus integrantes assumir o estigma ou a satisfação de pertença, dependendo da posição hierárquica ocupada.

A concepção idealizada de família é um tema que merece reflexão mais detalhada no que diz respeito aos/as jovens pesquisados, cuja origem, a partir de toda a trajetória empreendida, tornou-se uma condição inviável. A perspectiva expressa sempre foi pautada em torno de um redirecionamento de vida, após a finalização do ciclo de institucionalização, que possibilitasse, de alguma forma, o retorno à família biológica ou a uma família substituta por meio do instituto da adoção, porém, as idades desses/as jovens tornam a adoção uma estratégia de possibilidade remota. Já os/as jovens com famílias localizadas são orientados/as a retornar ao convívio familiar. Essa condição, para muitos/as deles/as, é a única vislumbrada.

Durante o longo período de institucionalização dos/as jovens, suas famílias não tiveram as condições modificadas, nem o motivo pelo qual assumiram o estatuto de miséria e menor valia que colocou em risco a sua prole. Constatamos que existem jovens que se sentem responsáveis por seus pais e irmãos que se encontram em dificuldade econômica. Foi sempre esse o discurso de verdade institucional que os/as acolhidos/as ouviram ao longo de suas existências. 0 que pudemos observar foi que os/as jovens não estão preparados/as para lidar com a realidade fora da instituição. Assim, eles/as transitam entre o desejo de ter uma família idealizada e a certeza de sua inexistência.

A função estratégica da família, em se tratando de uma gestão biopolítica como instância de disciplina e controle, deve ser preservada. Por esse motivo, os regimes de saberes que em torno da família circulam nas entidades denotam a intenção de reforçá-la, de enaltecê-la, de privilegiá-la. Esses/as sujeitos, corpos que o processo de institucionalização docilizou, disciplinou no lugar da família, modificando a condição anterior de fator de risco, são orientados/as, depois de adultos/as, a retornar a esse lugar. Os/as jovens desejam, sim, uma família, mas uma família diferente da existente, uma vez que o regime de verdade, os saberes que lhes foram repassados e subjetivados, é bastante diferente do modelo familiar que eles/elas têm na realidade. Os/as jovens não desejam uma família que venha reforçar ainda mais o estatuto de "nascido vivo" (sic) que eles/as já assumem em função da institucionalização a que se submeteram ao longo de suas vidas.

0 fato de retornar ao ambiente familiar, o que não foi capaz de lhes assegurar laços consanguíneos e afetivos da forma instituída socialmente, os/as submete, novamente, a uma situação que extrapola normas, que foge a regras, razão sufi- 
ciente para os/as colocar novamente em estado de exceção, e, portanto, possibilitar a sua reinserção ao estatuto de "nascido vivo" (sic) já vivenciado institucionalmente. Esse sentimento pode deixar claro um dos aspectos subjetivos produzidos pela interação de saberes, difundido com a prática de acolhimento institucional prolongada.

A rotina vivenciada dentro das entidades, como regimes de saberes, atos de obediência e de verdade, é identificada na fala dos/as jovens entrevistados/as como algo a que são submetidos, que acatam, mas que os faz sentirem-se entediados.

Acordar, merendar, depois vai estudar um pouquinho; depois chega $11 \mathrm{~h} 30 \mathrm{~min}$, almoça. Uma hora, vai pra escola; cinco horas, chega. Aí, depois, janta 6 horas, e 9 horas é a ceia. Aí 10h30min o recolhimento, dormir. No final de semana é a mesma coisa, não tem nada pra fazer aqui dentro. (Gabriela, 18 anos)

0 caráter humanista do regime de verdade da prática de acolhimento é expresso na percepção que os/as jovens pesquisados/as têm das unidades que os acothem, ao comparar sua vida com a daqueles/as jovens que vivem nas ruas. Embora tenham colocado sua insatisfação sobre o cotidiano do acolhimento, ao mesmo tempo, ressaltam que ter casa, cama e comida, para eles/elas, é uma dádiva que os/as situa numa posição privilegiada em relação aos/às jovens que estão na rua, redundando em uma obrigação de reconhecimento e agradecimento.

Aqui nós passeia, brinca, come, dorme, e na rua não tem isso. Na rua nós sofre, faz o mal pra nós e pros outros. Tem a dormida, que é ótima, tenho uma bolsa. (Messias, 19 anos)

Cada um tem a sua caminha, tem a comida, tem aula, tem curso. (Silvia, 19 anos)

As falas de aceitação da vida institucionalizada não se restringem ao fato de ter moradia, cama e comida, mas também de como essas coisas asseguram viver em conformidade com o padrão socialmente estabelecido.

Assim, eu acho bom morar aqui porque aqui eu tenho casa, tenho tudo aqui, tenho estrutura. Eu acho que sou um vencedor porque eu saí da rua, então, assim, eu tenho roupa, eu tenho cama, eu tenho leite, e tenho irmãos... E num é todo adolescente que sofre na vida, mas um dia tem essas coisas, educação, respeito, então eu sou agradecido. Primeiramente a Deus, ao governo, aliás, às pessoas que querem ver você bem, sei lá... Se eu fosse agradecer, ia ser tanta gente, que eu ia passar o dia todinho e não ia dar. (Ivan, 18 anos)

0 discurso positivo em relação à instituição se respalda na experiência de abandono e violência a que foram submetidos anteriormente. Por isso, o abrigo é visto como lugar de proteção e apoio, além de ser a única alternativa que os/as jovens 
possuem.

Outro aspecto relevante é o sentimento de culpa que aparece no discurso de vários jovens ao serem indagados sobre sua baixa escolaridade.

A culpa é de mim mesma. Porque oportunidade é que não falta, porque todo mundo aqui ajuda, dá conselho, ensina o que é certo e o que é errado. (Cristiane, 20 anos, lê e escreve com dificuldade, cursa $1^{\circ}$ ano do ensino médiol

Eu estudei, mas não queria saber de nada, não levava a sério. Aí repeti. Foi por mim mesmo, porque eu não quis mesmo. Não culpo ninguém não, foi falta de interesse. (Gabriel, 19 anos lê e escreve com dificuldade, cursa $1^{\circ}$ ano do ensino médio)

A culpa retratada pelos/as jovens institucionalizados/as mostra a visão negativa que eles/as tem de si. Um dos entrevistados, ao contar a sua história de acolhimento prolongado, encontra motivos, os mais variados, e culpa a si próprio por um ato impensado, assim justificado:

E eu sei também como eu sou teimoso. Até agora eu sou teimoso ainda. Sou muito curioso. Aí eu resolvi ir lá fora ver a chuva. É porque esse negócio de chuva, negócio de tomar banho de chuva. A minha casa tava aberta, a porta debaixo. É aquelas portas que abre assim, embaixo. A de baixo tava aberta e a de cima tava fechada, e era pra ser o contrário, pra mim não passar. Aí eu peguei e abri. Não, tava aberta e eu fiz só empurrar, aí pronto. Aí deu uma "brechinha" e eu fui andando, fui tomando banho de chuva até o ponto que tava longe. Aí, na hora que eu me virei, eu fiquei assim confuso e não me lembrava mais qual era a casa. Aí eu resolvi andar mesmo, tomar banho de chuva. Andando, andando até depois de algumas horas eu cheguei numa casa, na casa de uma mulher. Aí ela viu que eu tava sozinho, não tinha ninguém, aí ela pegou e me acolheu. Fiquei muito tempo, acho que eu fiquei uns três anos, mais ou menos. Foi um bom tempo. Do meu pai, irmão, lembro não. Apagou tudo. Aí, depois eu comecei... depois que eu encontrei essa mulher, que ela me acolheu, aí pronto, aí que começou a minha vida. Não fiquei com ela por causa das condições, porque ela tinha só um trabalho. 0 marido dela não trabalhava e ela tinha um filho pra criar. No começo ela me deixava numa creche, ela ia trabalhar e eu ficava na creche. Cheguei no abrigo foi por causa de denúncia anônima. Descobriram que eu não tinha nem pai nem mãe, que eu tava morando na casa da mulher por morar mesmo. Ilegal. Agora eu acho que culparia a mim, porque eu já tive chance de ser adotado várias vezes e eu não quis. Porque eu sou muito danado, preguiçoso, curioso. Saudade eu tenho mesmo de morar nessa família aí, de morar com essa mulher aí. Tudo isso que aconteceu foi por eu mesmo. (João, 20 anos)

As falas relatadas denotam o efeito da lógica da "governamentalidade" neoliberal. Como na sociedade contemporânea o estatuto de nascimento não é significado como um benefício de fato, os sujeitos são classificados de acordo com a posição ocupada; se bem, são sancionados; se mal, são apenados. 0/a jovem acolhido/a sabe muito bem discernir, nessa escala, o lugar que the é destinado e tem esse 
fato como um ato de verdade que o/a faz ser grato/a a todos os que o/a rodeiam pelos serviços que the foram prestados e, portanto, ao reconhecer-se culpado/a, age no sentido de decretar e aceitar a própria pena, isentando a culpa dos que se encontram ao seu lado.

Um dos discursos institucionais mais apontados nas falas dos/as entrevistados/as, indicado por eles como uma "verdade", foi, ao longo do tempo, se justificando sem a necessidade da verdade científica da justiça, da lei que eles/as não conhecem, apenas ouviram falar, mas nem por isso deixam de acreditar; percepção esta encontrada nas mais variadas falas e situações:

0 que eles falaram é que eu num ia ficar lá muito tempo, que, assim que se resolvesse, eu ia pra casa. Aqui é um lugar pra passar não esses anos todos, é pra passar apenas um período. Era pra gente ter passado aqui muito pouco tempo. Só que aí o juiz botou pra gente passar num sei quanto tempo, né? Era pra gente arranjar uma família [...] eu acredito que seja a outra equipe, né? Que não fez esse vínculo da gente com a família. Aí quebrou muito. Eu passei muitos anos sem ver minha família. Eu ia lá um dia, uma vez, e era muito demorada a ida. [...] quando chega uma idade, a gente quer sair, né? Se divertir, e aqui num pode por causa do juizado, do juiz, que não deixa ter a liberdade e é o que todo adolescente quer. (Cristiane, 20 anos)

Trata-se, ainda, de um jogo de troca, entre poderes (Executivo e Judiciário), de isenção de responsabilidades, onde um atribui culpa ao outro pela situação encontrada. Com isso, vemos reforçado o pensamento de Foucault (2004), acerca de a racionalidade política neoliberal ser fundamentada em torno da impossibilidade de conciliar o direito (sistema jurídico) à ordem (sistema administrativo). Ele salienta ser desnecessário buscar a razão dessa racionalidade política, dessa tecnologia política, apenas, na forma de integração do direito à ordem do Estado. Segundo ele, a procura dessa razão deve ser baseada na dinâmica das relações no interior da sociedade vigente.

Talvez por isso possamos compreender os motivos de o Estatuto da Criança e do Adolescente (ECA) não ter sido mencionado em nenhum momento das entrevistas efetuadas. Parece até não fazer parte do vocabulário dos pesquisados. 0 seu conteúdo parece nunca ter sido informado. Contudo, o que foi repassado e constituiu um regime de saber assimilado como verdade aos jovens pesquisados para justificar as suas longas permanências em entidades de acolhimento institucional dispensou a necessidade do discurso jurídico como critério de legitimidade de verdade científica. Observa-se aí um exemplo em que a presença da lei não se fez necessária à manutenção da ordem institucional.

Outro aspecto observado, também identificado em outras instâncias sociais, como a família e a escola, foram as normas e as disciplinas que, nas entidades de acolhimento, também funcionam como regimes de verdade que não devem ser contestados e, segundo os/as investigados/as, acabam se tornando medidas ne- 
cessárias. As regras da casa são modelos nem sempre aceitáveis, e, embora o seu descumprimento não implique punição, são interpretadas como um fator de positividade, sendo vislumbrada, no futuro, a sua reprodução. Em síntese, os discursos de verdade que circulam livremente e dispensam a figura autorizada para serem reconhecidos pelo sujeito como verdadeiros, no âmbito da obediência e da disciplina institucional observada, também dispensam a presença de mecanismos coercitivos e repressores. Exigem apenas o reconhecimento do sujeito que se realiza por meio de novos dispositivos atuantes na produção de uma subjetividade marcada pela submissão e sujeição que tais discursos de verdade deixam nos/as jovens.

Os/as jovens pesquisados/as têm o nível de escolaridade bastante defasado. Essa realidade, até então pouco pensada, só começa a se constituir numa dificuldade encontrada no momento em que se aproxima o alcance da idade-limite de permanência na instituição. Buscar superar tal condição é a esperança apontada pelos/as entrevistados/as.

Ainda não sei ler, faço a $1^{\mathrm{a}}$ série à noite, vou pra $2^{\mathrm{a}}$ série agora. Porque também eu não estudava lá na outra escola, eu não estudei na outra casa, porque a escola que tinha não tinha a minha série. Estudava, mas mudou pra casa nova, aí não tinha outro lugar pra mim ficar. Eu peço muito pra depois fazer um curso de cozinheiro, qualquer curso. Aí, uma vez, eu já fiz curso de bombeiro, de bombeiro mesmo. (Lucas, 19 anos)

A projeção de futuro desses/as jovens segue, assim, modulada de acordo com as inserções conquistadas por meio dos gestores institucionais em espaços de escolarização, profissionalização e empregabilidade, cuja condição de conseguir, em curto prazo, meios de subsistência próprios encontra-se bem distante de suas realidades.

Observamos que o estatuto de "nascido vivo" (sic), que submete esses/as jovens a essa trajetória de escolarização e profissionalização, sem desconsiderar as fragilidades existentes nesses campos, produz modos de subjetivação que os/as remete à condição de dificuldade de aprender a ler, a estagiar, a trabalhar. Em consequência desse fato, aliado à situação de instabilidade financeira e habitacional futura, aparece a insegurança e o medo que os/as imobiliza diante das oportunidades de avançar nessa direção.

\section{0 estatuto de liberdade}

A condição de abandono familiar torna os/as jovens reféns das políticas sociais de assistência à infância e à adolescência, e a longa etapa de suas vidas em instituições de acolhimento trouxe, certamente, elementos significativos na produção subjetiva desses sujeitos. 
Os/as jovens, em seus discursos, enfatizaram a vontade de romper com a vida governada e conquistar a liberdade, ou seja, de romper os muros da instituição e seguir em busca de outra direção, atitude não empreendida em face do despreparo e da insegurança de que são detentores.

A noção habitual de liberdade é vinculada ao livre arbítrio, à possibilidade de satisfazer as próprias vontades, como dono/a de seus pensamentos, senhor/a dos seus atos, chefe de si próprio. Foi em torno dessa perspectiva que o tema da liberdade foi ressaltado por todos os/as entrevistados/as como o maior desejo a ser conquistado.

A saída, a gente deveria sair, ter mais liberdade. É porque eu sei que não tem em nenhum abrigo, mas também devia ter um pouquinho mais de liberdade. (Wesley, 19 anos)

Práticas de liberdade, de autonomia, como observa o próprio jovem, não há em nenhum abrigo, pois a instituição funciona como proteção e controle dos corpos. Ao oferecer proteção, também cerceia a liberdade dos internos.

Quando a gente vai sair, tem que ir acompanhado do educador, porque aqueles que não são maiores de idade têm que sair acompanhado do educador, né? Aí dá raiva da gente, às vezes, não puder sair sozinho. Pois é, são essas coisas. Eu quero sair daqui e ter minha vida. Num quero passar o resto da minha vida num abrigo. 0 abrigo é só uma história, e eu quero construir a minha historia fora, com uma família. (Ivan, 18 anos)

Os/as jovens compreendem o caráter transitório da vida no abrigo, das relações que estabeleceram, embora tenham permanecido muito tempo na instituição. $A$ vigilância, a disciplina, são efeitos de relações de poder que perpassam o cotidiano do abrigo.

Aí o nosso problema é esse, a liberdade. Tem uma adolescente aí, a irmã da Gabriela, que o sonho dela aqui era a liberdade, aí ela saiu daqui, porque ela fez 18 anos e queria logo sair, então ela saiu e foi lá pra irmã dela. Eu fico reparando se é bom a liberdade ou se era bom ficar dentro do abrigo, que dentro do abrigo a gente tem segurança, fora do abrigo a gente não tem segurança. Mais ou menos isso. (Cristiane, 20 anos)

Atingir a maioridade é o fator propulsor de liberdade. 0 medo e a insegurança de enfrentar o mundo lá fora constituem algo que os leva a tornar esse momento num tempo sempre adiado.

Arranjar o primeiro emprego fica mais fácil enquanto tiver aqui no abrigo. Você passa mais uns dois anos só juntando, juntando e, quando tiver com uns 20 anos, comprar uma casa. (Jarlan, 18 anos, $1^{\circ}$ ano do ensino médio) 
Durante as entrevistas, ao falarem sobre como se sentiam para enfrentar a vida fora da entidade, os/as jovens expressam insegurança e medo.

Não sei, depende. Se a minha família me aceitasse. Mas eu não queria sair daqui, não. Desde pequeno eu tenho esse conceito. Quando eu sair daqui, eu quero ajudar a minha mãe e viver minha vida, quero sair daqui trabalhando. (Gabriel, 19 anos, $1^{\circ}$ ano do ensino médio, dificuldades na leitura e na escrital

A experiência prolongada de abrigamento produz marcas e sentimentos que acompanham os/as jovens em toda a sua trajetória. No cotidiano, as normas, os mecanismos disciplinares, são práticas que produzem efeitos nos modos de existência desses/as jovens. 0 momento de saída do abrigo requer autonomia e os/as jovens não se sentem preparados/as para viver sem o controle e proteção institucional.

Sinceramente, eu vou dizer que, agora, não. Mais ou menos preparado, mas o que dá pra fazer eu tô fazendo; o que botar pra onde eu ir eu tô indo. Eu vou enfrentar como eu enfrentei morar em abrigo, que é muito difícil. Lá fora vai ser mais um desafio pra mim, que eu vou superar também. (João, 20 anos, $3^{\circ}$ ano do ensino médio)

Não, eu não estou preparada, porque, bem dizer, é só eu e meu irmão, né? Tem que ser só nós dois, porque minha família nem se fala, né? Porque primeiro quem vai me ajudar é meu irmão, então, não vai ser fácil, porque eu não estou preparada pra sair daqui pra cuidar duma casa. (Silvia, 19 anos, EJA V, $8^{\circ} / 9^{\circ}$ ano, alfabetizada recentemente)

Essas falas expressam como os/as jovens foram se acomodando à vida institucionalizada. As normas, os códigos se inscrevem nos seus corpos, por isso a saída do abrigo é tão difícil, gera tanta insegurança. Como enfrentar o mundo lá fora? Como caminhar sem proteção, sem vigilância? Para onde ir? Essas questões são postas para os/as jovens de abrigo quando atingem 18 anos.

Eu acho que a gente tá muito aqui dentro, a gente se sente segura que a gente fica tanto aqui dentro, que, quando sai, a gente fica com medo de pegar ônibus, qualquer coisa deixa a gente insegura, com tanta proteção. Porque proteção é bom, mas tem que ver o outro lado também, que a gente num vai tá sempre protegido. Um dia nós vai ter que sair, viver, nós vamos ter que andar sozinho, né? Com as nossas perna. Num vai ter ninguém pra fazer o que faziam antes. É pra gente sair desse abrigo. Já dá pra gente sair, só que eu não quero sair agora. (Cristiane, 20 anos)

As manifestações de verdade que os/as jovens vivenciam como sujeitos dessa realidade são, também, reforçadas pela condição de testemunhas da trajetória vivenciada pelos companheiros que já deixaram a entidade. Ao comparar a dimensão da liberdade com as dificuldades encontradas fora da entidade, o medo e a 
insegurança postergam o sonho de rompimento com a sujeição que vivenciam.

Acho muito ruim. As meninas tudo grávida lá do colégio. Menina de 13 anos tudo grávida já. Eu acho que aqui eu sou mais protegida. As minhas irmãs, uma casou só pra sair logo. $\mathrm{Na}$ época, ela gostava dele, mas agora ela não tá gostando muito não. Teve filho foi cedo ela. Agora que ela tá trabalhando, começou agora. A outra, eu acho que não dava pra ela ter saído agora não, tia. Ela só saiu pra ter liberdade. (Gabriela, 17 anos, $1^{\circ}$ ano do ensino médio, lê com dificuldade)

Foucault (2008), na obra "Nascimento da Biopolítica", mostra como se processa a lógica autorreflexiva do neoliberalismo, que lhe permite ser tão sutil, invasivo, autoajustável, ilimitável, sendo praticamente impossível enfrentá-lo, compreendê-lo, sem conhecê-lo. Para Foucault, o indivíduo só passa a ser alvo de interesse pelo Estado em função de sua utilidade política.

E é dentro da concepção biopolítica que Foucault (2008, p. 285) ressalta a ação do Governo em intervir e "[...] assistir os que dele necessitam naquele momento e somente naquele momento em que deles necessitam." Fundamentado nesse mesmo argumento, o Governo tenta justificar as ações contingenciais que efetua no campo assistencial.

A liberdade foucaultiana, segundo Larrosa (2000), não se refere à concepção ordinária do termo, que surge do exercício reflexivo acerca da realidade que aprisiona ou do sujeito que domina. Encontra-se, porém, ao lado do exercício da prática, da experimentação, da subversão, da revolução. Para o autor, não se pode falar da liberdade de forma deliberada, ou seja, em que não se aplica a noção de libertação da liberdade, mas a existência positiva dos limites da liberdade. Portanto, o que pode ser analisado não é a liberdade em si, mas “[...] a destruição da liberdade, a manipulação da liberdade, a limitação da liberdade". (Larrosa, 2000, p. 333)

Ao refletir sobre a política de assistência social de acolhimento institucional, é possível se notar a presença da lógica da inclusão, cujo objetivo era afastar da sociedade o risco, a ameaça, o perigo que esses sujeitos representavam. Essa razão inclusiva, entretanto, por ser fundamentada pela racionalidade política do neoliberalismo, também é expressa, na prática, pelo risco da exclusão, fato que aterroriza os/as jovens ao pensar em se afastar da zona de segurança e de amparo social que a instituição lhes proporciona. Longe desse espaço, na lógica do regime de "governamentalidade" neoliberal.

\section{Considerações Finais}

Ao conhecermos a experiência de acolhimento dos/das jovens pesquisados/as, observamos que o cuidado com os/as abandonados/as saiu do âmbito da caridade cristã e da filantropia para a tutela do Estado, que direciona, na atualidade, tal 
atividade às entidades privadas - ONGs, repetindo a mesma lógica da benemerência revestida de um novo modelo de solidariedade, fundamentada no discurso do "resgate" da cidadania - como se fosse possível reaver algo que jamais foi conquistado. A descentralização do Estado torna mais econômico e eficaz governar a conduta dos indivíduos, ao difundir por meio da gestão das ONGs a ele vinculado uma relação de saber que dificulta condutas de contrapoder - atitude dual e discurso ambíguo; novas práticas de "governamentalidade" neoliberal.

A pesquisa mostra o aumento do número de entidades de acolhimento institucional em relação à década anterior, entretanto, não foi possível fazer um mapeamento exato em função de muitas entidades existirem sem o conhecimento dos órgãos responsáveis pelo registro oficial dessa atividade.

Quando os jovens atingem a maioridade, a política de assistência social de acolhimento institucional acaba por afastá-los da zona de segurança e de amparo social que a instituição anteriormente lhes proporcionava. 0 regime de "governamentalidade" induz esses/as jovens a cuidarem de si mesmos/as, ainda que eles/ elas não tenham quaisquer condições de assumir suas vidas fora da instituição.

Ao conhecermos a trajetória de vida dos/as jovens que se encontram em acothimento institucional por um longo período, percebemos que esses/as jovens, mesmo tendo sua vida capturada pelo biopoder, pela estatística da vulnerabilidade, buscam formas de resistência, que estão ancoradas em sua própria memória, na projeção de sonhos, no desejo de encontros e reencontros com a família e na espera que algo aconteça para que possam construir uma vida diferente.

Verificamos que a exclusão desses/as jovens se revela pelo caráter de invisibilidade que hoje representam. Eles/as não perturbam, não mobilizam, não alteram a ordem do mundo. São indivíduos normalizados pelas políticas de inclusão. As suas existências não preocupam. Para essa faixa etária, não são previstas mudanças, nem no contexto de acolhimento, tampouco nas relações que em seu interior acontecem. A vida deles/as parece não ter pressa. Assim, sua permanência naqueles espaços de inclusão acaba sendo prorrogada.

Durante o percurso de institucionalização dos/as jovens pesquisados/as, constatamos que a desvalorização dessas vidas é expressa com o registro de suas histórias. A gestão das unidades de acolhimento, de acordo com a política implantada, transfere os acolhidos para outra casa, conforme a idade atingida. Ali, além do tempo de "captura", muito de suas histórias fica naquela entidade; estas thes foram "sequestradas"; ficaram confinadas, certamente, no porão de suas memórias, porque das instituições eles/elas se mudaram, mas os registros de suas vidas, muitas vezes, não os/as acompanharam. Outras vezes, não foram para eles/ elas repassadas e sequer consultadas, ficando apenas a fazer volume nas gavetas dos armários dos arquivos institucionais. O Poder Judiciário, que armazena a documentação durante todo o período de acolhimento, constitui um dos acervos cronológicos dessas histórias, encaminha-as, por meio de um documento judicial, para o arquivo institucional quando esses sujeitos atingem a idade de 18 anos. 
Informam que, por tal razão, os tutelados fogem à competência daquele juízo. $\mathrm{Na}$ maioria das vezes, todavia, um relatório conclusivo da situação do/a acolhido/a, no momento do arquivamento, não é apresentado. 0 critério de obtenção da idadelimite, simplesmente, justifica o arquivamento, e aquela vida não representa mais necessidade de registro.

Os/as jovens, quando pensam em deixar a instituição, sentem-se inseguros/as independentemente de sua condição educacional e/ou econômica. A segurança que afirmam sentir lá dentro faz parte da proteção que existe no imaginário de cada jovem acolhido. Suas trajetórias atestam que, depois de terem conseguido percorrer uma longa jornada, em diversas entidades de acolhimento institucional, encontram-se agora diante de uma "vida nua", separados de seus contextos familiares de origem; sobreviveram, de certa forma, à morte.

\section{Referência Bibliográfica}

AGAMBEN, Giorgio. Homo sacer: o poder soberano e a vida nua. Tradução de Henrique Burigo. 2. ed. Belo Horizonte: Editora UFMG, 2010.

BONFIM, Lihana M. C. Sexualidade e adolescência: uma investigação com adolescentes masculinos com experiência de rua, e em situação de abrigo. 2009 (166 f) Tese (Doutorado em Educação Brasileira) - Universidade Federal do Ceará, Fortaleza, 2009.

FOUCAULT, Ética, sexualidade, política. Michel Foucault: organização e seleção de textos. Manoel Barros da Mota. Rio de Janeiro: Forense Universitária, 2004. (Ditos e Escritos, v. 5).

Fontes, 2008.

Nascimento da biopolítica. Tradução Eduardo Brandão. São Paulo: Martins

Vigiar e punir: história da violência nas prisões. Petrópolis: Vozes, 1987.

LARROSA, Jorge. A libertação da liberdade. In: PORTOCARREO, Vera; CASTELO BRANCO, Guilherme (Org.). Retratos de Foucault. Rio de Janeiro: Nau, 2000. p. 328335.

GOFFMAN, E. Manicômicos, prisões e conventos. Trad.: Dante Moreira Leite, $7^{\mathrm{a}}$ Ed., São Paulo, Perspectiva, 2005.

. Estigma: notas sobre a manipulação da identidade deteriorada. Rio de Janeiro. Zahar Editores, 1975.

PELBART, Vida nua, vida besta, uma vida. Texto apresentado em palestra proferida no Festival de Alcântara, Teatro São Luiz. Lisboa, 2006.

ROCHA, Francisca Helena. Subjetividade e prostituição infanto-juvenil. 1999, (129 f.). Dissertação (Mestrado em Psicologia) - Universidade de Fortaleza, Fortaleza, 1999. SALES, Celecina de Maria Veras. Criações coletivas da juventude no campo político: um olhar sobre os assentamentos rurais do MST. Fortaleza: BNB, 2006. 
Recebido em janeiro de 2013

Aprovado em maio de 2013

Celecina Sales é doutora em educação com pós-doutorado em sociologia, e professora da pós-graduação em educação da Universidade Federal do Ceará. Coordena a linha de pesquisa "Movimentos socias, educação popular e escola”. Email: celecinavs@agmail.com

Francisca Helena Rocha é doutora em educação pela Universidade Federal do Ceará. Pesquisa sobre os temas juventude; proteção social, e biopolítica. Email: fca.helenaahotmail.com 